\title{
Sources of sodium in Australian children's diets and the effect of the application of sodium targets to food products to reduce sodium intake
}

\author{
Carley A. Grimes, Karen J. Campbell, Lynn J. Riddell and Caryl A. Nowson* \\ Centre for Physical Activity and Nutrition Research, School of Exercise and Nutrition Sciences, Deakin University, \\ Melbourne VIC 3125, Australia \\ (Received 17 March 2010 - Revised 20 July 2010 - Accepted 16 August 2010 - First published online 28 September 2010)
}

\begin{abstract}
The average reported dietary Na intake of children in Australia is high: $2694 \mathrm{mg} / \mathrm{d}$ (9-13 years). No data exist describing food sources of Na in Australian children's diets and potential impact of Na reduction targets for processed foods. The aim of the present study was to determine sources of dietary $\mathrm{Na}$ in a nationally representative sample of Australian children aged 2-16 years and to assess the impact of application of the UK Food Standards Agency (FSA) Na reduction targets on Na intake. Na intake and use of discretionary salt (note: conversion of salt to $\mathrm{Na}, 1 \mathrm{~g}$ of $\mathrm{NaCl}$ (salt) $=390 \mathrm{mg} \mathrm{Na}$ ) were assessed from 24-h dietary recall in 4487 children participating in the Australian 2007 Children's Nutrition and Physical Activity Survey. Greatest contributors to Na intake across all ages were cereals and cereal-based products/ dishes (43\%), including bread (13\%) and breakfast cereals (4\%). Other moderate sources were meat, poultry products (16\%), including processed meats ( $8 \%$ ) and sausages (3\%); milk products/dishes (11\%) and savoury sauces and condiments (7\%). Between 37 and $42 \%$ reported that the person who prepares their meal adds salt when cooking and between 11 and $39 \%$ added salt at the table. Those over the age of 9 years were more likely to report adding salt at the table $\left(\chi^{2} 199 \cdot 5\right.$, df $\left.6, P<0 \cdot 001\right)$. Attainment of the UK FSA Na reduction targets, within the present food supply, would result in a $20 \%$ reduction in daily Na intake in children aged $2-16$ years. Incremental reductions of this magnitude over a period of years could significantly reduce the $\mathrm{Na}$ intake of this group and further reductions could be achieved by reducing discretionary salt use.
\end{abstract}

Key words: Dietary sodium: Children: Dietary salt: Australia

The link between high dietary $\mathrm{Na}$ intake and elevated blood pressure in adults is well established ${ }^{(1,2)}$. Lifetime reduction in dietary salt intake is likely to reduce risk of $\mathrm{CVD}^{(3)}$. Recent evidence indicates that dietary Na can contribute to higher levels of blood pressure during child$\operatorname{hood}^{(4)}$. Throughout life, blood pressure follows a tracking pattern, in which those children with elevated blood pressure are more likely to have raised blood pressure as adults ${ }^{(5,6)}$. These findings highlight the importance of commencing salt reduction strategies during early life. Furthermore, past studies have demonstrated the tracking of dietary patterns from childhood to adolescence ${ }^{(7)}$ and adulthood $^{(8)}$, indicating that early exposure to highly salted foods may increase the likelihood of these dietary patterns continuing into adulthood.

In the most developed countries, dietary $\mathrm{Na}$ in adults and children exceeds dietary recommendations ${ }^{(9)}$. The majority $(75-80 \%)$ of dietary $\mathrm{Na}$ is derived from salt added to processed foods ${ }^{(10)}$. To reduce population salt intake, Na needs to be reduced in the food supply, through the manufacture of lower-Na foods ${ }^{(9,11,12)}$. The UK has been at the forefront of this approach, wherein 2006, the Food Standards Agency (FSA) released voluntary $\mathrm{Na}$ reduction targets for food products ${ }^{(13)}$. These targets were developed to encourage food manufacturers to reduce $\mathrm{Na}$ levels in a range of processed foods to aid in the progression towards reducing population salt intake to $6 \mathrm{~g} / \mathrm{d}^{(13)}$. This approach has been successful in the UK where since the release of the $\mathrm{Na}$ reduction targets in 2006, the daily salt consumption in adults has fallen from $9.5 \mathrm{~g}$ in 2001 to $8.6 \mathrm{~g}$ in $2008^{(14)}$. In Australia, in April 2010, voluntary $\mathrm{Na}$ reduction targets were released for both bread and breakfast cereals ${ }^{(15)}$. Unlike the UK, a comprehensive list of $\mathrm{Na}$ reduction targets for a range of processed foods is not yet available in Australia. The Australian Division of World Action on Salt and Health is working towards the development of $\mathrm{Na}$ reduction targets for other processed foods. An overall aim of the Australian

Abbreviations: CNPAS, Children's Nutrition and Physical Activity Survey; FSA, Food Standards Agency; SES, socio-economic status. 
Division of World Action on Salt and Health is to reduce Australian adults' daily salt intake to $6 \mathrm{~g}(\mathrm{Na}$ $2300 \mathrm{mg}$ ) by $2012^{(16)}$

The most recent data available examining dietary $\mathrm{Na}$ intake in Australian children are from the 2007 National Children's Nutrition and Physical Activity Survey

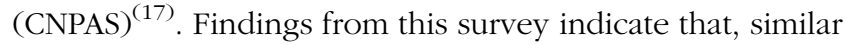
to other developed nations such as the $\mathrm{UK}^{(18)}$ and the $\mathrm{USA}^{(19)}$, Australian children are consuming high levels of dietary $\mathrm{Na}$, with average daily intakes (excluding discretionary use of salt at the table or in cooking) of $1675 \mathrm{mg}$ (salt $4.2 \mathrm{~g}$ ), $2161 \mathrm{mg}$ (salt $5.4 \mathrm{~g}$ ), $2694 \mathrm{mg}$ (salt $6.7 \mathrm{~g}$ ) and $3161 \mathrm{mg}$ (salt $7 \cdot 9 \mathrm{~g}$ ) in 2-3 year olds, 4-8 year olds, 9-13 year olds and $14-16$ year olds, respectively ${ }^{(17)}$. In Australia, the National Health and Medical Research Council recommends an adequate daily $\mathrm{Na}$ intake of $200-400 \mathrm{mg}$ (salt $0 \cdot 5-1.0 \mathrm{~g}$ ), 300-600 mg (salt $0.75-1.5 \mathrm{~g}$ ), 400-800 mg (salt $0 \cdot 5-2 \cdot 0 \mathrm{~g}$ ) and $460-920 \mathrm{mg}$ (salt $1 \cdot 2-2 \cdot 3 \mathrm{~g}$ ); and an upper limit of $1000 \mathrm{mg}$ (salt $2.5 \mathrm{~g}$ ), $1400 \mathrm{mg}$ (salt $3.5 \mathrm{~g}$ ), $2000 \mathrm{mg}$ (salt $5 \mathrm{~g}$ ) and $2300 \mathrm{mg}$ (salt $5.75 \mathrm{~g}$ ), in children aged $2-3,4-8,9-13$ and $14-18$ years, respectively ${ }^{(20)}$. With comparison to these recommendations, it is evident that children's $\mathrm{Na}$ intake is excessively high and public health policy to reduce dietary $\mathrm{Na}$ intake in children is urgently required.

In order to reduce $\mathrm{Na}$ intake in children, it is necessary to identify the major sources of $\mathrm{Na}$ in children's diets. In the present study, we utilised data from the 2007 CNPAS to identify the major dietary sources of $\mathrm{Na}$ in children's diets, the frequency of discretionary salt use and associated demographic characteristics in Australian children aged 2-16 years. Additionally, we applied the most recently revised 2012 UK FSA Na reduction targets to Australian food products to investigate the effect these targets have on $\mathrm{Na}$ intake in Australian children.

\section{Subjects and methods}

\section{Australian National Children's Nutrition and Physical Activity Survey}

The full details of the methodology used in the CNPAS have been previously reported ${ }^{(21)}$. A brief overview of the methodology relevant to our analysis is described in a later section. Participants were recruited using a multistage quota sampling framework. The initial target quota was 1000 participants for each of the following age groups: $2-3,4-8,9-13$ and $14-16$ years, to which a 400 booster sample was later provided by the state of South Australia. Postcodes were randomly selected as stratified by state/territory and capital city/rest of state. Randomly selected clusters of postcodes ensured an equal number of participants in each age group, from each of the metro and non-metro areas within each state. Random digit dialling was used to invite eligible households, those with children aged 2-16 years, within selected postcodes to participate in the study. Only one child from each household could participate in the study. The response rate of households was $40 \%$. Due to the non-proportionate nature of the sampling framework, each participant was assigned a population weighting which weighted for age, sex and region. The study was approved by the National Health and Medical Research Council registered Ethics Committees of Commonwealth Scientific Industrial Research Organisation and University of South Africa.

Data were collected at two time points, between February and August 2007, the first consisting of a face-to-face interview (computer-assisted personal interviewing) which was followed by a telephone (computer-assisted telephone interviewing) interview. A total of 4487 children completed all the components of the survey. Only data from the computer-assisted personal interview are included in this analysis $^{(22)}$. Demographic data were collected for both the participating child and the primary caregiver. A three-pass $24 \mathrm{~h}$ dietary recall was used to determine all food and beverages consumed from midnight to midnight on the day before the interview. The three-pass method includes the following stages: (i) provide a quick list of all foods and beverages, (ii) a series of probe questions relevant to each quick list item to gather more detailed information such as portion size and brand name and (iii) finally, a recall review to validate information and make any necessary adjustments ${ }^{(21)}$ Portion sizes were estimated using a food model booklet and standard household measures. Na intake, along with other nutrients, was calculated using the Australian nutrient composition database AUSNUT 2007, specifically developed by the Food Standards Australia and New Zealand for the CNPAS $^{(23)}$. Each food and beverage item recorded was matched to an eight-digit food code, which corresponded to a set of nutrient data. Each eight-digit food code was derived from a five-digit food code that represented 'minor' food categories. Each minor food category falls under a three-digit sub-major food category, which then falls within a two-digit major food category. A detailed list of the food group classification system can be found in the CNPAS user guide ${ }^{(21)}$.

In addition, the participants completed a food habits questionnaire, which included two questions relating to discretionary salt use: 'Does the person who prepares your meal add salt when they are cooking?' and 'Do you add salt to your meal at the table?' Participants could respond yes, usually; yes, sometimes; no; or I do not know. Both the $24 \mathrm{~h}$ dietary recall and food habits questionnaire were conducted with the primary caregiver of participants aged 9 years and under, and with the study child in those participants aged 9 years and over. The primary caregiver was encouraged to be present for all the interviews. In the case where children under the age of 9 years were away from the home, a 'caregiver form' was provided to the alternative carer to record dietary intake over the recall period. This information was added to the dietary recall during the interview ${ }^{(21)}$. 


\section{Data analysis}

Food sources of sodium. The CNPAS food group coding system $^{(21)}$ was used to calculate the contribution of $\mathrm{Na}$ from major, sub-major and minor food groups. The contribution of each major, sub-major and minor food group to daily $\mathrm{Na}$ intake was calculated using the following formula:

$\%$ of $\mathrm{Na}$ from food group $=($ sum of $\mathrm{Na}$ from food group

$(\mathrm{mg}) /$ total sumof $\mathrm{Na}$ from all foods $(\mathrm{mg})) \times 100$.

The food group contribution calculations were preformed separately for each age group, 2-3, 4-8, 9-13 and 14-16 years, with population weightings applied.

Application of sodium reduction targets. The FSA revised $2012 \mathrm{Na}$ reduction targets ${ }^{(24)}$ were used as a benchmark to determine the percentage reduction of $\mathrm{Na}$ content required in Australian food products for them to comply with the FSA targets. Within the UK's FSA targets, subcategories have been assigned either a maximum or an average target level of $\mathrm{Na}$ permitted per $100 \mathrm{~g}$ of food. Where possible we have utilised the average level targets in preference to the maximum levels set. It should be noted that the recently set $\mathrm{Na}$ target for Australian bread by the end of 2013 is identical to the target set by the FSA for regular breads and bread rolls (i.e. $400 \mathrm{mg}$ / $100 \mathrm{~g})^{(15)}$. The Australian Na reduction target for breakfast cereals differs from the UK system, in that a $15 \%$ reduction in the Na content of ready-to-eat breakfast cereals has been set, rather than a $\mathrm{Na}$ content level in $\mathrm{mg} / 100 \mathrm{~g}$. The $15 \%$ reduction applies only to those breakfast cereals that exceed $400 \mathrm{mg}$ of $\mathrm{Na}$ per $100 \mathrm{~g}^{(15)}$. For consistency in this analysis, we have utilised the FSA targets.

To calculate the average $\mathrm{Na}$ content $(\mathrm{mg} / 100 \mathrm{~g})$ of Australian food products, the sum of $\mathrm{Na}$ provided by all foods consumed within either a sub-major or a minor food category was divided by the sum of $\mathrm{g}$ of food consumed within that sub-major or minor food category, multiplied by 100 . These calculations were preformed on the full dataset ( $n$ 4487), with population weightings applied.

$\mathrm{Na}$ reduction targets were applied to those food categories which contain processed foods where reductions in $\mathrm{Na}$ levels can be achieved; this accounted for eleven of the twenty-two major food group categories. It was not suitable to apply Na targets within the other eleven categories as these include fresh foods and those with minimal levels of $\mathrm{Na}$, for example, non-alcoholic beverages, fruit products and dishes and sugar products and dishes. The selected eleven major food categories were further broken down into sub and minor categories to determine if an appropriate FSA target could be matched to the Australian food category. It was not possible to assign certain categories with an FSA target due to differences between the Australian food group classification system and that used by the FSA. To avoid missing these categories, for which FSA has targets for but do not match to the Australian categories, we applied a 'blanket' $25 \%$ reduction. For example, although the FSA has set a target for a range of different types of savoury sauces, these could not be applied to Australian food categories as too much variation exists between the two classification systems. As this category consists of high-Na food items which contribute significantly to $\mathrm{Na}$ intake, hence we applied a 25\% 'blanket' target to these categories. We chose $25 \%$, as it has been previously demonstrated that at this level, no change in taste of the food products is detected by the consumer ${ }^{(25)}$. Furthermore, this is the level recommended by Australian Division of World Action on Salt and Health to reduce the level of salt in food products and within the catering industry ${ }^{(16)}$.

To calculate the percentage reduction required in $\mathrm{Na}$ content of each food group category to meet the FSA target, the following formula was used:

$\%$ reduction in $\mathrm{Na}$ content to meet FSA target

$=($ estimated mean $\mathrm{Na}$ content of Australian food

category $(\mathrm{mg} / 100 \mathrm{~g})$ - FSA Na reduction

target $(\mathrm{mg} / 100 \mathrm{~g}) /$ estimated mean $\mathrm{Na}$ content of

Australian food category $(\mathrm{mg} / 100 \mathrm{~g})) \times 100$.

The percentage reduction was then applied to the mean $\mathrm{Na}$ intake coming from each food group category for each age group to calculate the new mean daily $\mathrm{Na}$ intake.

Assessment of under-reporting. To assess the validity of reported energy intake (EI) at the group level, the EI:estimated BMR ratio was calculated for each age group, using Schofield equations ${ }^{(26)}$, and compared to the appropriate Goldberg cut-off $(1.52)^{(27,28)}$. At the group level, the calculated EI:estimated BMR was 1.67, 1.77, 1.55 and 1.49 in 2-3, 4-8, 9-13 and 14-16 year olds, respectively. This indicates a small degree of under-reporting at the group level in 14-16-year-old participants. To assess the level of over-reporting, we calculated the percentage of participants whose EI exceeded three standard deviations from the mean EI for their age group. On average, only $1 \%$ of the participants were classified as over-reporters. In the present analysis, no participants were excluded on the basis of under- or over-reporting.

\section{Statistical analysis}

The frequency of participants, in each age group, reporting discretionary salt use was calculated using descriptive statistics. We used the highest level of education attained by the primary carer as a marker for socio-economic status (SES). Based on this, the participants were grouped into one of the three categories of education attainment: (i) high, includes those with a university/tertiary qualification; (ii) mid, includes those with an advanced diploma, diploma or certificate III/IV or trade certificate; and 
(iii) low, includes those with some or no level of high school education. Significant relationships between categorical variables were determined using $\chi^{2}$ analysis. A $P$ value of $<0.05$ was considered significant. Data and statistical analyses were performed with PASW version 17 (PASW, Inc., Chicago, IL, USA) and Microsoft Excel (Microsoft Corporation, Redmond, WA, USA).

\section{Results}

\section{Food sources of sodium}

The relative contribution of each major food group to total daily $\mathrm{Na}$ intake in children by age group is shown in Fig. 1. Across all age groups, the greatest contributor to $\mathrm{Na}$ intake was cereals and cereal products, accounting for over $20 \%$ of intake. Other major sources, contributing to more than $10 \%$ of intake across most age groups, are cereal-based products and dishes; meat, poultry and game products; and milk products and dishes. The contribution of each major food category to $\mathrm{Na}$ intake was relatively similar across all age groups. Except for cereal-based products and dishes, which accounted for a greater contribution to $\mathrm{Na}$ intake in older children; and milk products and dishes, which accounted for a greater contribution to $\mathrm{Na}$ intake of children in the younger age groups.

Table 1 lists those major, sub-major and minor food categories that contributed to more than $2 \%$ of daily $\mathrm{Na}$ intake in any age group. Within the cereals and cereal products category, regular breads and bread rolls contributed the greatest proportion to $\mathrm{Na}$ intake across all age groups (12-15\%). Pastries contributed between 3 and $6 \%$ of $\mathrm{Na}$ intake across age groups and tended to increase with age. Within the meat, poultry and game products and dishes, processed meat made the greatest contribution to
$\mathrm{Na}$ intake ranging from 7 to $9 \%$, followed by sausages, frankfurts and saveloys accounting for $2-3 \%$. Both dairy milk (3-7\%) and cheese (4-7\%) contributed the most $\mathrm{Na}$ within the milk products and dishes. Other moderate sources of $\mathrm{Na}$ across all age groups were gravies and savoury sauces (5-8\%), soup (2-3\%) and snack foods (2-4\%).

\section{Application of Food Standards Agency sodium reduction targets}

Of the 263 minor food categories that were investigated within the eleven major categories, an appropriate FSA target could be applied to eighty-five of the minor food categories. The $25 \%$ 'blanket' reduction was applied to an additional eighty-one minor food categories. The remaining ninety-seven minor food categories that were not assigned a $\mathrm{Na}$ reduction target included fresh food items and those with negligible Na levels. These included rice and grains ( $n$ 6), vegetable oils ( $n$ 6), fresh fish and seafood ( $n$ 5), fresh meat and poultry ( $n$ 13), milk, yoghurt and cream ( $n$ 45), vegetables ( $n$ 17), herbs, spices and sweeteners $(n 5)$.

Table 2 shows those Australian food categories that were assigned either an FSA $\mathrm{Na}$ reduction target or a blanket $25 \%$ reduction target. For the ease of reporting rather than listing all (166) minor food categories, this has been condensed, so that those minor food categories within a sub-category that were all assigned the same target are only presented once as the sub-category.

Six Australian food groups were found to have an estimated Na content level already lower than that of the proposed FSA target; these included sweet breads, buns and scrolls; sweet breads, buns and scrolls, fortified; breakfast cereal, hot porridge type; cheese, natural, traditional;

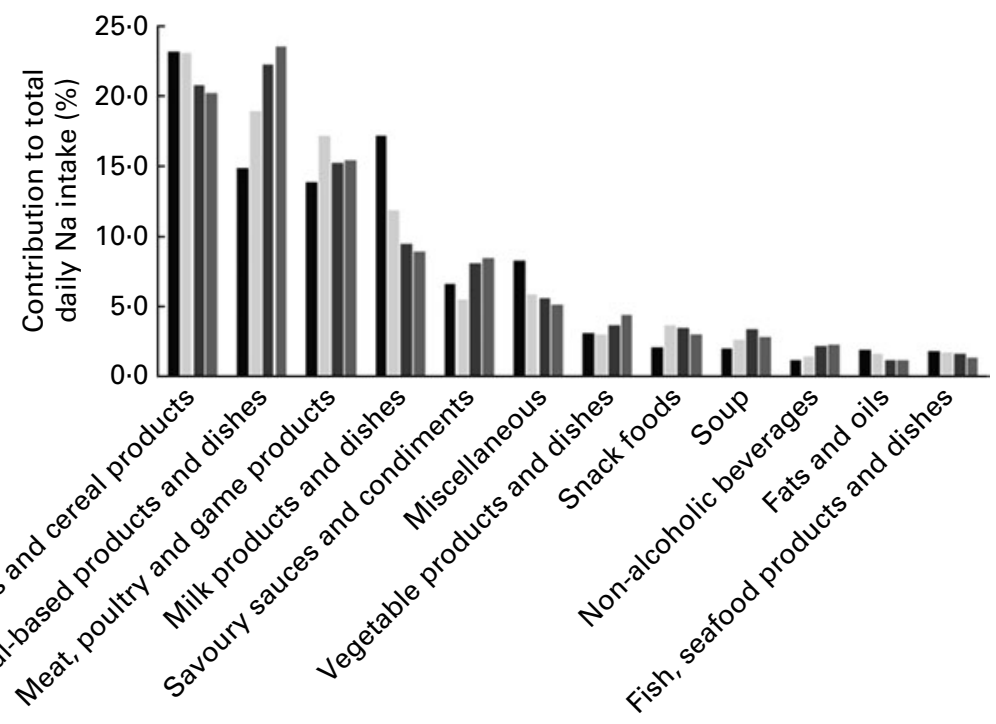

Food category

Fig. 1. Sources of $\mathrm{Na}$ from major food groups in Australian children aged $2-16$ years ( $n$ 4487). $\mathbf{\square}, 2-3$ years, $n 1071$; $\square, 4-8$ years, $n 1216$; $\square$, 9-13 years, $n$ 1110; $\square, 14-16$ years, $n 1090$. 
Table 1. Main food sources of sodium from major, sub-major and minor food categories in 2-16-year-old Australian children (food group categories that contribute $>2.0 \%$ of sodium to daily intake across any age group are included, $n$ 4487)

\begin{tabular}{|c|c|c|c|c|}
\hline \multirow[b]{2}{*}{ Food group name } & \multicolumn{4}{|c|}{ Age group (years) } \\
\hline & $2-3(n 1071)$ & $4-8(n 1216)$ & $9-13(n 1110)$ & $14-16(n$ 1090) \\
\hline Non-alcoholic beverages & $1 \cdot 1$ & 1.4 & $2 \cdot 2$ & $2 \cdot 2$ \\
\hline Cereals and cereal products (total \%) & 23.2 & 23.1 & $20 \cdot 8$ & $20 \cdot 2$ \\
\hline Regular breads and bread rolls & 14.9 & $15 \cdot 0$ & 12.5 & $12 \cdot 3$ \\
\hline Breads and bread rolls, white & $6 \cdot 0$ & $7 \cdot 0$ & $7 \cdot 0$ & $7 \cdot 0$ \\
\hline Breads and bread rolls, mixed grain & $2 \cdot 4$ & 1.7 & 1.4 & 1.6 \\
\hline Breads and bread rolls, wholemeal & 3.1 & $2 \cdot 3$ & 1.7 & 1.4 \\
\hline English style muffins, flat breads and savoury sweet biscuits & $2 \cdot 2$ & $2 \cdot 4$ & $2 \cdot 3$ & $2 \cdot 7$ \\
\hline Breakfast cereals and bars, unfortified and fortified varieties & 4.7 & 4.2 & 4.3 & 3.8 \\
\hline Breakfast cereal, wheat based, fortified & 1.6 & 1.2 & 0.9 & 0.9 \\
\hline Cereal-based products and dishes (total \%) & 14.9 & 18.9 & $22 \cdot 3$ & 23.6 \\
\hline Sweet biscuits & 1.5 & 1.3 & 1.1 & 1.1 \\
\hline Savoury biscuits & $2 \cdot 8$ & 2.6 & $2 \cdot 1$ & 1.6 \\
\hline Cakes, buns, muffins, scones, cake-type desserts & $2 \cdot 0$ & 2.6 & $2 \cdot 3$ & $2 \cdot 3$ \\
\hline Cakes, cake mixes & 1.2 & 1.6 & 1.1 & 1.3 \\
\hline Pastries & 3.0 & $4 \cdot 0$ & $5 \cdot 3$ & 5.9 \\
\hline Savoury pastry products, pies, rolls and envelopes & $2 \cdot 1$ & 3.5 & 4.5 & $5 \cdot 0$ \\
\hline Mixed dishes where cereal is the major ingredient & $4 \cdot 0$ & $6 \cdot 8$ & $9 \cdot 4$ & $11 \cdot 3$ \\
\hline Pizza & 0.9 & $2 \cdot 1$ & 3.0 & 4.2 \\
\hline Sandwiches and filled rolls (where recipe not known) & 0.3 & 0.6 & 1.5 & 1.9 \\
\hline Hamburgers & 0.2 & 1.3 & 1.8 & $2 \cdot 0$ \\
\hline Savoury pasta or noodle and sauce dishes & 1.9 & 1.8 & 1.7 & 1.3 \\
\hline Batter-based products & 1.5 & 1.6 & $2 \cdot 0$ & 1.4 \\
\hline Fats and oils & 1.9 & 1.6 & 1.1 & 1.1 \\
\hline Fish and seafood products and dishes & 1.8 & 1.7 & 1.6 & 1.3 \\
\hline Meat, poultry and game products and dishes (total \%) & 13.8 & $17 \cdot 1$ & $15 \cdot 2$ & $15 \cdot 4$ \\
\hline Sausages, frankfurts and saveloys & 3.1 & $3 \cdot 1$ & 3.2 & $2 \cdot 0$ \\
\hline Sausage & $2 \cdot 4$ & $2 \cdot 3$ & $2 \cdot 3$ & 1.4 \\
\hline Processed meat & $6 \cdot 5$ & $9 \cdot 2$ & $6 \cdot 6$ & 7.4 \\
\hline Bacon & 0.8 & 1.6 & 1.6 & $2 \cdot 2$ \\
\hline Ham & $4 \cdot 1$ & $5 \cdot 0$ & 3.0 & $3 \cdot 2$ \\
\hline Processed delicatessen meat, red & 1.5 & $2 \cdot 3$ & 1.5 & 1.5 \\
\hline Mixed dishes where poultry or game is the major component & 1.9 & $2 \cdot 8$ & 2.5 & $2 \cdot 9$ \\
\hline Poultry or game crumbed, battered, meatloaf or patty type & 1.6 & $2 \cdot 3$ & 1.7 & $2 \cdot 0$ \\
\hline Milk products and dishes (total \%) & $17 \cdot 2$ & 11.8 & $9 \cdot 4$ & 8.9 \\
\hline Dairy milk & $7 \cdot 3$ & $4 \cdot 2$ & 3.6 & 3.0 \\
\hline Milk, cow, fluid, regular whole, full fat & $5 \cdot 8$ & $2 \cdot 8$ & $2 \cdot 1$ & 1.8 \\
\hline Yoghurt & 1.7 & 0.9 & 0.5 & 0.5 \\
\hline Cheese & $7 \cdot 1$ & $5 \cdot 3$ & 3.8 & 4.0 \\
\hline Cheese, natural, traditional & $4 \cdot 2$ & 3.0 & 2.5 & 2.9 \\
\hline Soup (total \%) & $2 \cdot 0$ & $2 \cdot 6$ & 3.3 & $2 \cdot 8$ \\
\hline Soup (prepared, ready to eat) & 1.9 & $2 \cdot 3$ & 3.0 & $2 \cdot 5$ \\
\hline Savoury sauces and condiments (total \%) & 6.5 & 5.5 & $8 \cdot 1$ & $8 \cdot 4$ \\
\hline Gravies and savoury sauces & $5 \cdot 7$ & 4.8 & 7.5 & 7.5 \\
\hline Savoury sauces & 3.7 & 3.1 & $4 \cdot 8$ & $5 \cdot 0$ \\
\hline Vegetable products and dishes (total \%) & 3.0 & 3.0 & 3.7 & 4.3 \\
\hline Potatoes & $1 \cdot 2$ & 1.6 & $2 \cdot 0$ & $2 \cdot 3$ \\
\hline Snack foods (total \%) & $2 \cdot 0$ & 3.6 & 3.5 & $2 \cdot 9$ \\
\hline Potato snacks & 0.8 & 1.6 & 1.9 & 1.8 \\
\hline Potato crisps & 0.8 & 1.6 & 1.9 & 1.7 \\
\hline Miscellaneous (total \%) & $8 \cdot 2$ & $5 \cdot 8$ & $5 \cdot 6$ & $5 \cdot 1$ \\
\hline Yeast, vegetable and meat extracts & 3.7 & 2.5 & 1.6 & 1.4 \\
\hline Herbs, spices, seasonings and stock cubes & 4.5 & 3.3 & $4 \cdot 0$ & 3.6 \\
\hline Salt & 3.3 & 2.6 & 3.3 & $2 \cdot 8$ \\
\hline
\end{tabular}

potato products (e.g. potato chips wedges and hash brown) (Table 2). Therefore, for each of these food groups, no adjusted calculation was made, as this would have resulted in an increase in mean $\mathrm{Na}$ intake from these food groups.

The percentage reduction in $\mathrm{Na}$ required to meet the proposed FSA targets varied considerably among food groups, ranging from 9 to $64 \%$. The majority of food groups $(75 \%)$ require reductions of greater than $20 \%$ in $\mathrm{Na}$ to reach the proposed FSA target. Those minor food groups that require the greatest reductions $(>40 \%)$ are sweet pastry products, tarts and flans (49\%), sweet pastry products, pies, slices and Danishes (42\%), sausage ( $41 \%)$, bacon (40\%), ham (57\%), processed delicatessen meat, red (43\%), all processed and fresh cheeses (40-64\%) and canned condensed soup (64\%). Application of the proposed Na reduction targets results in the following changes in mean daily $\mathrm{Na}$ intake $(\mathrm{mg})$ to each of the age groups: $2-3$ years, $1674-1347$ (salt $4 \cdot 2-3 \cdot 4 \mathrm{~g}$ ); 4-8 
Table 2. Application of sodium reduction targets to Australian food categories

\begin{tabular}{|c|c|c|c|}
\hline Australian food category name & $\begin{array}{c}\text { Mean Na content } \\
(\mathrm{mg} / 100 \mathrm{~g})\end{array}$ & $\begin{array}{c}\text { FSA Na content target } \\
(\mathrm{mg} / 100 \mathrm{~g})\end{array}$ & $\begin{array}{c}\% \text { Reduction in } \mathrm{Na} \\
\text { to reach target }\end{array}$ \\
\hline \multicolumn{4}{|l|}{ Cereals and cereal products } \\
\hline Regular breads and bread rolls (plain/unfilled/untopped varieties) & 482 & 400 & 17 \\
\hline \multicolumn{4}{|l|}{ English-style muffins, flat breads and savoury sweet breads } \\
\hline English-style muffins & 476 & 300 & 37 \\
\hline Flat breads (e.g. pita bread) & 467 & 400 & 14 \\
\hline Savoury filled or topped breads and bread rolls & 664 & 480 & 28 \\
\hline Savoury filled or topped breads and bread rolls & 659 & 480 & 27 \\
\hline Sweet breads, buns and scrolls & 226 & 300 & -33 \\
\hline Sweet breads, buns and scrolls, fortified & 273 & 300 & -10 \\
\hline Tortilla, taco shells and corn bread & 466 & 400 & 14 \\
\hline Breakfast cereals and bars, unfortified and fortified varieties & 385 & 270 & 30 \\
\hline Breakfast cereal, hot porridge type & 28 & 270 & -859 \\
\hline \multicolumn{4}{|l|}{ Cereal-based products and dishes } \\
\hline Sweet biscuits & 296 & 270 & 9 \\
\hline Savoury biscuits & 755 & 550 & 27 \\
\hline Cakes, buns, muffins, scones, cake-type desserts & 323 & 200 & 38 \\
\hline \multicolumn{4}{|l|}{ Pastries } \\
\hline Pastry, croissant & 335 & 300 & 10 \\
\hline Sweet pastry products, tarts and flans & 254 & 130 & 49 \\
\hline Sweet pastry products, pies, slices and Danishes & 225 & 130 & 42 \\
\hline Savoury pastry products, tarts and flans & 378 & 300 & 21 \\
\hline Savoury pastry products, pies, rolls and envelopes & 538 & 450 & 16 \\
\hline Mixed dishes where cereal is the major ingredient & 425 & $25 \%$ Reduction & 25 \\
\hline Batter-based products & 489 & 300 & 39 \\
\hline \multicolumn{4}{|l|}{ Fats and oils } \\
\hline Butters & 531 & $25 \%$ Reduction & 25 \\
\hline Dairy blends & 434 & $25 \%$ Reduction & 25 \\
\hline Margarine and table spreads & 510 & $25 \%$ Reduction & 25 \\
\hline \multicolumn{4}{|l|}{ Meat, poultry and game products and dishes } \\
\hline \multicolumn{4}{|l|}{ Sausages, frankfurts and saveloys } \\
\hline Sausage & 763 & 450 & 41 \\
\hline Frankfurts and saveloys & 758 & 650 & 14 \\
\hline \multicolumn{4}{|l|}{ Processed meat } \\
\hline Bacon & 1901 & 1150 & 40 \\
\hline Ham & 1507 & 650 & 57 \\
\hline Processed delicatessen meat, red & 1140 & 650 & 43 \\
\hline Processed delicatessen meat, white & 748 & 600 & 20 \\
\hline Canned processed meat & 1055 & 650 & 38 \\
\hline Mixed dishes where beef, veal or lamb is the major component & 193 & $25 \%$ Reduction & 25 \\
\hline Mixed dishes where pork, bacon or ham is the major component & 283 & $25 \%$ Reduction & 25 \\
\hline Mixed dishes where poultry or game is the major component & 354 & $25 \%$ Reduction & 25 \\
\hline \multicolumn{4}{|l|}{ Milk products and dishes } \\
\hline \multicolumn{4}{|l|}{ Cheese } \\
\hline Cheese, natural, traditional & 676 & 720 & -7 \\
\hline Cheese, natural, reduced fat and fat modified & 567 & 720 & -27 \\
\hline Cheese, cottage and cheese, cottage, low fat & 277 & 220 & 21 \\
\hline Cheese, cream and cheese, cream, reduced fat & 575 & 220 & 62 \\
\hline Cheese, processed & 1331 & 800 & 40 \\
\hline Cheese, processed, reduced fat & 1440 & 800 & 44 \\
\hline Cheese, processed, fortified & 1368 & 800 & 42 \\
\hline Cheese, camembert, brie & 605 & 220 & 64 \\
\hline \multicolumn{4}{|l|}{ Soup } \\
\hline Soup (prepared, ready to eat) & 257 & 230 & 10 \\
\hline Dry soup mix & 1883 & $25 \%$ Reduction & 25 \\
\hline Canned condensed soup (unprepared) & 645 & 230 & 64 \\
\hline Savoury sauces and condiments & 783 & $25 \%$ Reduction & 25 \\
\hline Vegetable products and dishes & & & \\
\hline Potatoes & & & \\
\hline Potato products (e.g. potato chips wedges and hash brown) & 162 & 195 & -21 \\
\hline Snack foods & & & \\
\hline Potato snacks & 674 & 550 & 18 \\
\hline Corn snacks & 523 & $25 \%$ Reduction & 25 \\
\hline Extruded or reformed snacks & 1038 & 750 & 28 \\
\hline Pretzels & 1980 & $25 \%$ Reduction & 25 \\
\hline Other snacks & 867 & $25 \%$ Reduction & 25 \\
\hline Miscellaneous & & & \\
\hline Yeast, vegetable and meat extracts & 2958 & $25 \%$ Reduction & 25 \\
\hline Herbs, spices, seasonings and stock cubes & & & \\
\hline Salt & 37038 & $25 \%$ Reduction & 25 \\
\hline Stock cubes and seasoning & 16920 & $25 \%$ Reduction & 25 \\
\hline Stock, prepared & 375 & $25 \%$ Reduction & 25 \\
\hline
\end{tabular}

FSA, Food Standards Agency. 
years, 2160-1705 (salt 5.4-4.3 g); 9-13 years, 2678-2135 (salt $6 \cdot 7-5 \cdot 3 \mathrm{~g}$ ); $14-16$ years, $3132-2503$ (salt $7 \cdot 8-6.3 \mathrm{~g}$ ). The greatest reductions in daily $\mathrm{Na}$ intake would be in those children within the older age groups, $629 \mathrm{mg} / \mathrm{d}$ (salt $1.6 \mathrm{~g} / \mathrm{d}$ ) and $543 \mathrm{mg} / \mathrm{d}$ (salt $1.4 \mathrm{~g} / \mathrm{d}$ ) in $14-16$ and 913 year olds, respectively, compared to $327 \mathrm{mg} / \mathrm{d}$ (salt $0.8 \mathrm{~g} / \mathrm{d})$ and $455 \mathrm{mg} / \mathrm{d}(1.3 \mathrm{~g} / \mathrm{d})$ in $2-3$ and $4-8$ year olds, respectively. However, as daily $\mathrm{Na}$ intake increases with age this would equate to a similar percentage reduction in mean $\mathrm{Na}$ intake across all age groups: 20, 21, 20 and 20\% in $2-3,4-8,9-13$ and $14-16$ year olds, respectively. Fig. 2 displays the difference these reductions would make to the percentage of children exceeding the recommended daily upper limit of $\mathrm{Na}$. The application of the proposed $\mathrm{Na}$ reduction targets results in 15, 20, 21 and $17 \%$ fewer children aged $2-3,4-8,9-13$ and $14-16$ years, respectively, exceeding the daily upper limit of $\mathrm{Na}$ for that age group.

\section{Discretionary salt use}

Approximately, $40 \%$ of the participants from all age groups reported that the person who prepares their meal either usually or sometimes adds salt when cooking (Fig. 3(a)). There was no significant difference between age group and salt added during cooking (Pearson $\chi^{2} 7 \cdot 6$, df 6 , $P=0 \cdot 266$ ). In contrast, there was a significant relationship between the age group and participants' own use of table salt. As participants aged, they were more likely to add salt at the table (Pearson $\chi^{2} 199 \cdot 5$, df 6, $P<0.001$ ). Of participants, $11,25,37$ and $39 \%$ aged $2-3,4-8,9-13$ and 14-16 years, respectively, reported adding salt to their meal at the table usually or sometimes (Fig. 3(b)). With regards to SES, there was no association between SES and salt added during cooking (Pearson $\chi^{2} 3 \cdot 87$, df

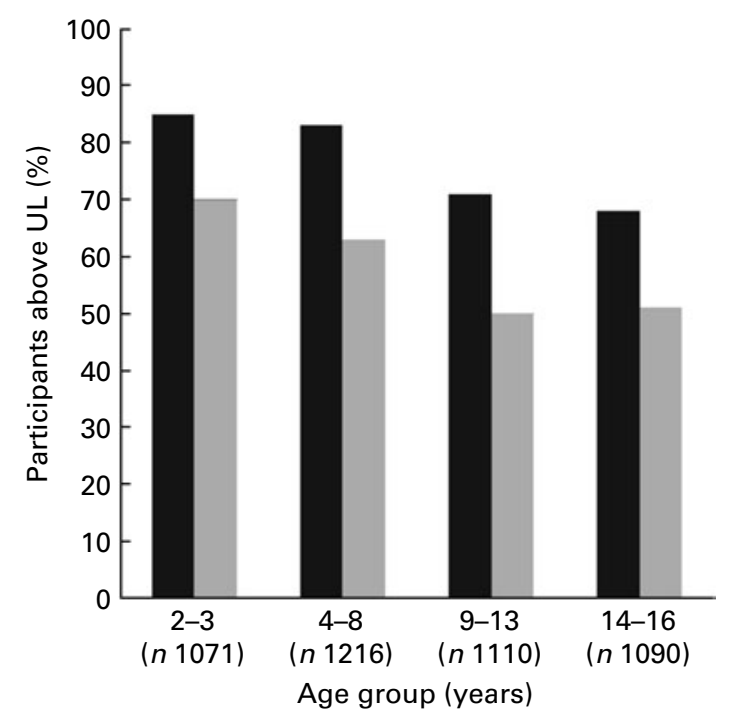

Fig. 2. Change in percentage of participants exceeding the suggested daily upper limit (UL) for $\mathrm{Na}$ before and after the application of $\mathrm{Na}$ reduction tar-

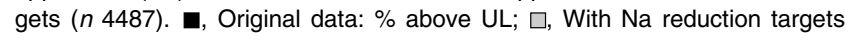
applied: \% above UL.
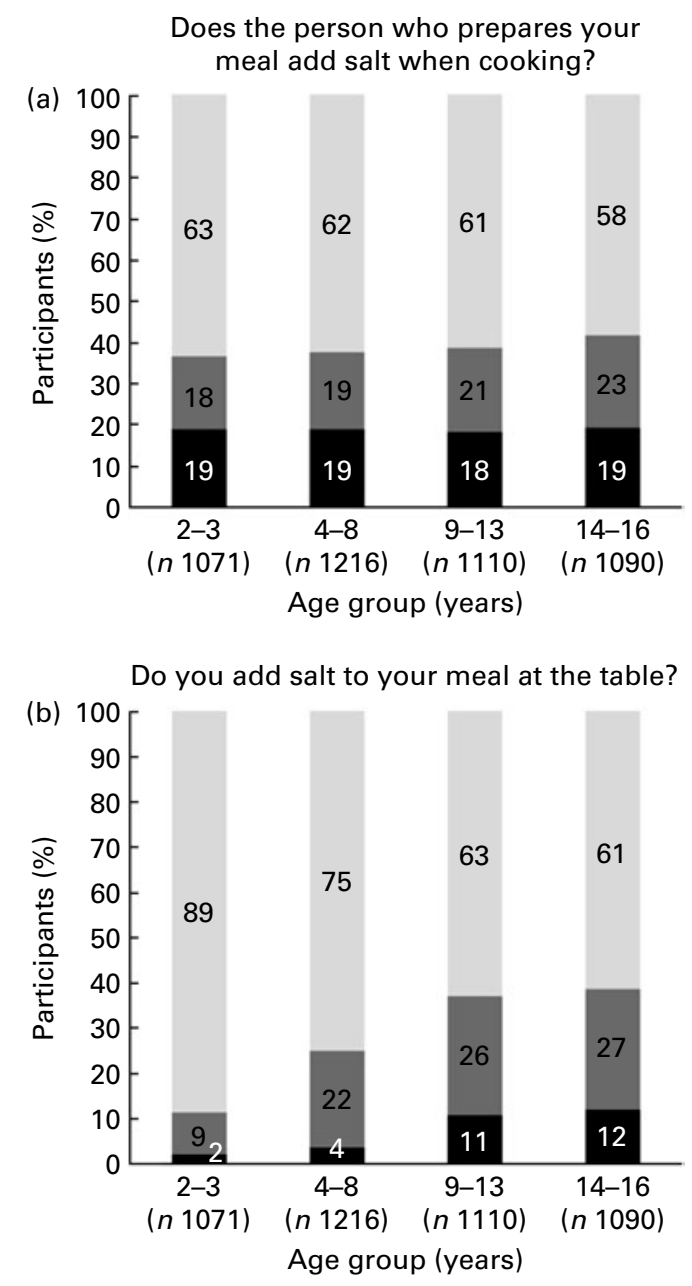

Fig. 3. Discretionary salt use in Australian children aged 2-16 years ( $n$ 4481) population weightings applied (those participants who responded 'do not know' ( $n 6)$ were excluded from this analysis) (a) salt added when cooking and (b) salt added at the table. $\square$, No; $\square$, Yes, sometimes; $\square$, Yes, usually.

4, $P=0$.425) (data not shown). There was a significant association between SES and salt added at the table (Pearson $\chi^{2} 42.53$, df 4, $\left.P<0 \cdot 001\right)$. Of participants, 33, 32 and $25 \%$ grouped as low, mid and high SES, respectively, reported usually adding salt to their meal at the table usually or sometimes.

\section{Discussion}

This is the first study to examine the major sources of dietary $\mathrm{Na}$ in Australian children. We found the greatest contributors to $\mathrm{Na}$ intake were cereals and cereal-based products/dishes (43\%), meat poultry and game products (16\%), milk products/dishes (11\%) and savoury sauces and condiments (7\%). Our findings are similar to those reported in other industrialised countries ${ }^{(29)}$.

Findings from our analysis indicate that the adherence to the 2012 FSA Na reduction targets to Australian food products would lower the average $\mathrm{Na}$ intake of 2-16 year old Australian children by $20 \%$. This is a significant reduction and if applied incrementally over the next 10 
years could result in a significant reduction in $\mathrm{Na}$ intake and bring intakes closer to recommended levels. Gradual, incremental reductions in the salt content of processed foods can be achieved without consumers detecting the reduction ${ }^{(25)}$. Since the FSA began its salt reduction strategy in 2003/2004, which included the release of the $\mathrm{Na}$ reduction targets for food products in 2006, daily salt consumption in adults has fallen from $9.5 \mathrm{~g}$ in 2001 to $8.6 \mathrm{~g}$ in $2008^{(14)}$. Although adults are still consuming high levels of salt that are exceeding dietary recommendations, this decrease represents a positive change in the trend from previously increasing salt intakes ${ }^{(11)}$. The success of the FSA $\mathrm{Na}$ reduction targets is also seen within the changing food supply, where on average, the $\mathrm{Na}$ content has been reduced by $20-30 \%{ }^{(11)}$. Other countries are now taking action with respect to salt reduction ${ }^{(30-32)}$.

Based on the UK FSA model, the USA and Canada have developed similar $\mathrm{Na}$ reduction targets which specify the level of $\mathrm{Na}(\mathrm{mg} / 100 \mathrm{~g})$ permitted across a range of processed foods ${ }^{(30,32)}$. In comparison, Australia is lagging behind in the development of comprehensive Na reduction targets. In April 2010, Australia's Food and Health Dialogue released targets for bread $(400 \mathrm{mg} / 100 \mathrm{~g})$ and breakfast cereal $^{(15)}$. In contrast to the UK model, the target for breakfast cereal is based on a percentage reduction level (i.e. $15 \%$ ), applying only to those cereals where $\mathrm{Na}$ levels exceed $400 \mathrm{mg} / 100 \mathrm{~g}$. In the present analysis, we have calculated that for Australian breakfast cereals to comply with the FSA target a 30\% average reduction in $\mathrm{Na}$ content is needed. The range of Na levels across Australian breakfast cereals is large, varying from 4 to $1063 \mathrm{mg} / 100 \mathrm{~g}^{(33)}$. The application of a $15 \%$ reduction to those cereals at the top of the range in Na levels would still promote the manufacture of breakfast cereals with unacceptably high Na levels. Thus, it is recommended that the Na reduction target for Australian breakfast cereals be expressed in $\mathrm{mg} / 100 \mathrm{~g}$ and also be lowered in line with the UK target (average $270 \mathrm{mg} / 100 \mathrm{~g}$; maximum $400 \mathrm{mg} / 100$ ). Such a target will achieve greater reductions in population $\mathrm{Na}$ intake and allow for consistency in $\mathrm{Na}$ levels across food products, encouraging a level playing field for food manufacturers. Furthermore, targets set at levels in $\mathrm{mg} / 100 \mathrm{~g}$ are more useful for monitoring and evaluating $\mathrm{Na}$ levels over time.

We also found that salt is commonly added during cooking and at the table and this has been estimated to contribute $15 \%$ of total daily $\mathrm{Na}$ intake ${ }^{(10)}$. Therefore, there is a potential for further reductions to total $\mathrm{Na}$ intake if the use of discretionary salt is reduced. Findings from the Australian Division of World Action on Salt and Health 2008 consumer survey on parents' attitudes to salt and children revealed that over half ( $52 \%$ ) of respondents reported that their children were consuming salty snacks, such as chips and savoury biscuits, at least a few times a week $^{(34)}$. Variation in salty taste perception and liking is mostly caused by learned experiences rather than genetics $^{(35)}$, exposure to salt in foods after the age of 2 years results in a liking for salt in foods ${ }^{(36-38)}$. Exposure to foods containing salt provides a learning environment in which children are familiarised with products that are accepted in their specific dietary culture. As salt intake is reduced, adults appear to prefer food with less salt ${ }^{(39)}$, and this is probably related to the adaptation of taste receptors over the course of weeks to months ${ }^{(40)}$. One study has demonstrated that in children aged $12-13$ years, those who reported eating at fast food restaurants more than once a month had a greater preference for salty foods ${ }^{(41)}$. Salt reduction campaigns targeting younger children and their parents to reduce the use of discretionary salt could result in a lifelong reduction in salt intake.

In the present analysis after the application of the $\mathrm{Na}$ reduction targets, daily $\mathrm{Na}$ intake decreased by 327,455 , 543 and $629 \mathrm{mg}$ (salt $0.8,1.2,1.4$ and $1.6 \mathrm{~g}$ ) in $2-3,4-8$, 9-13 and 14-16 year olds, respectively. These findings highlight that incremental product reformulation of lower-Na foods will significantly reduce children's daily $\mathrm{Na}$ intake. However, as intakes will still be above levels recommended for health, this strategy should be combined with education and behavioural interventions to achieve greater reductions. Such interventions should aim to limit high-salt processed foods, e.g. savoury snacks and processed meats, and replace these with fresh foods which are low in salt.

The strength of the present study is that the data utilised come from a large national survey. The complex sampling methods employed in the CNPAS enabled the selection of the best available sample of Australian children aged 2-16 years within eligible postcodes. However, the study also has a number of limitations which should be considered when interpreting the findings. First, for determining the average Na content of Australian food products, our calculations were based on the foods that the participants had eaten on the day of the survey and nutrient values obtained from the nutrient composition database AUSNUT 2007 ${ }^{(23)}$. No laboratory analyses were conducted to determine $\mathrm{Na}$ values of food products and reported $\mathrm{Na}$ content was used. In addition, in the CNPAS Na intake was determined via 24-h dietary recall. This method fails to capture the amount of $\mathrm{Na}$ coming from salt added at the table and during cooking, and as such is likely to be an underestimation of the true value of $\mathrm{Na}$ intake. Furthermore, we acknowledge that there was a small degree of underreporting detected within the 14-16 year old age group. However, given the aims of the present study and the minor bias detected, it is unlikely that this would have affected our overall results. We applied FSA Na reduction targets to eighty-five minor Australian food categories and a $25 \%$ 'blanket' reduction on a further eighty-one minor food categories. This method ensured that the majority of processed foods that can be targeted in $\mathrm{Na}$ reduction were included in our analysis. One exception is canned vegetables, where due to the inclusion of both canned and fresh varieties grouped together in the Australian food group classification system, it was not possible to 
place a Na reduction target on this category. The contribution of vegetables (excluding potato) to $\mathrm{Na}$ intake in this sample of Australian children was low (1.6\%). As such it is unlikely that the omission of a target on this food group would significantly alter our overall results.

In summary, we have demonstrated that the application of $\mathrm{Na}$ reduction content targets on Australian food products could reduce the average $\mathrm{Na}$ intake of Australian children aged $2-16$ years by $20 \%$. This would reduce the present average $\mathrm{Na}$ intake, which is approximately 1.6 times the upper daily limit to an average level that is 1.2 times the upper level (currently $7 \cdot 8 \mathrm{~g}$ salt for $14-16$ year olds and $4 \cdot 2 \mathrm{~g}$ salt for $1-3$ year olds, excluding discretionary use of salt at the table or during cooking) and would result in approximately $20 \%$ fewer children exceeding the daily upper limit for $\mathrm{Na}$. Although this $20 \%$ may seem modest, it is likely that with regular review and consultation with the food industry, similar reductions could be achieved every 2-3 years, which would result in most children falling below the upper limit. For Australia, the UK's FSA targets provide a useful starting framework to guide population-wide Na reductions. Our findings also indicate that the reported frequency of discretionary salt is relatively high among Australian children. To successfully reduce $\mathrm{Na}$ intake, there is a need for salt reductions strategies to incorporate education campaigns that target both discretionary salt use and consumption of high salt processed foods. Successful implementation of these strategies will lead to a population-wide reduction in salt intake which will ultimately reduce rates of CVD.

\section{Acknowledgements}

We acknowledge Commonwealth Scientific Industry Research Organisation, University of South Australia and the Department of Health and Ageing in the collection of data. We acknowledge the Australian Social Science Data Archive for the availability of the datasets. We declare that those who carried out the original analysis and collection of the data bear no responsibility for the further analysis or interpretation of them. This project was supported by a post-graduate scholarship from the National Heart Foundation of Australia. The author's responsibilities were as follows: C. A. G., K. J. C., L. J. R. and C. A. N. helped in study design; C. A. G. helped in data analysis and writing of the manuscript; K. J. C., L. J. R. and C. A. N.: provision of significant advice and consultation, and revision of the manuscript. None of the authors has any conflicts of interest.

\section{References}

1. He FJ \& MacGregor GA (2002) Effect of modest salt reduction on blood pressure: a meta-analysis of randomized trials. Implications for public health. J Hum Hypertens 16, $761-770$
2. World Health Organization (2007) Reducing Salt Intake in Populations: Report of a WHO Forum and Technical Meeting. Paris: World Health Organization.

3. Ritz E \& Mehls O (2009) Salt restriction in kidney disease - a missed therapeutic opportunity? Pediatr Nephrol 24, 9-17.

4. He FJ, Marrero NM \& MacGregor GA (2008) Salt and blood pressure in children and adolescents. J Hum Hypertens 22 , $4-11$.

5. Lauer RM \& Clarke WR (1989) Childhood risk factors for high adult blood pressure: The Muscatine Study. Pediatrics $\mathbf{8 4}$, 633-641.

6. Mitsnefes MM (2006) Hypertension in children and adolescents. Pediatr Clin North Am 53, 493-512.

7. Kelder SH, Perry CL, Klepp K, et al. (1994) Longitudinal tracking of adolescent smoking, physical activity, and food choice behaviours. Am J Public Health 84, 1121-1126.

8. Mikkila V, Rasanen L, Raitakari OT, et al. (2004) Longitudinal changes in diet from childhood into adulthood with respect to risk of cardiovascular diseases: The Cardiovascular Risk in Young Finns Study. Eur J Clin Nutr 58, 1038-1045.

9. Brown IJ, Tzoulaki I, Candeias V, et al. (2009) Salt intakes around the world: implications for public health. Int $J$ Epidemiol 38, 791-813.

10. James PT, Ralph A \& Sanchez-Castillo CP (1987) The dominance of salt in manufactured food in the sodium intake of affluent societies. Lancet 329, 426-429.

11. He FJ \& MacGregor GA (2008) A comprehensive review on salt and health and current experience of worldwide salt reduction programmes. J Hum Hypertens 23, 363-384.

12. Keogh JB \& Clifton PM (2008) Salt intake and health in the Australian population. Med J Aust 189, 526.

13. Food Standards Agency (2009) New salt reduction targets published. http://www.food.gov.uk/news/newsarchive/2006/ mar/salttargets (accessed 23 November 2009).

14. Food Standards Agency (2009) Dietary sodium levels surveys. http://www.food.gov.uk/science/dietarysurveys/ urinary\%20 (accessed 12 December 2009).

15. Food and Health Dialogue (2010) Salt reduction targets agreed. Department of Health and Ageing. http://www. health.gov.au/internet/ministers/publishing.nsf/Content/mryr10-mb-mb022.htm?OpenDocument (accessed 25 July 2010).

16. Australian Division of World Action on Salt and Health (2009) Drop the Salt! Campaign. http://www.awash.org.au/ dropthesaltcampaign.html (accessed 23 November 2009).

17. Commonwealth Scientific Industrial Research Organisation (CSIRO), University of South Australia (2008) 2007 Australian National Children's Nutrition and Physical Activity Survey Main Findings. Canberra: Commonwealth Department of Health and Ageing, Australian Food and Grocery Council, Commonwealth Department of Agriculture, Fisheries and Forestry.

18. Gregory J, Lowe S, Bates CJ, et al. (2000) National Diet and Nutrition Survey: Young People Aged 4 to 18 Years. London: The Stationery Office.

19. Wright JD, Wang CY, Kennedy-Stehpenson J, et al. (2003) Dietary intake of ten key nutrients for public health. Adv Data Vital Health Stat 334, 1-4.

20. NHMRC (2006) Nutrient Reference Values for Australia and New Zealand. Canberra: National Health and Medical Research Council.

21. Commonwealth Scientific Industrial Research Organisation (CSIRO), University of South Australia (2008) User Guide 2007 Australian National Children's Nutrition and Physical Activity Survey. Canberra: Commonwealth Department of Health and Ageing, Australian Food and Grocery Council, Commonwealth Department of Agriculture, Fisheries and Forestry. 
22. Commonwealth Department of Health and Ageing, Australian Food and Grocery Council, Commonwealth Department of Agriculture Fisheries and Forestry (2008) The 2007 National Children's Nutrition and Physical Activity Survey [Computer File]. Canberra: Australian Social Science Data Archive, The Australian National University.

23. Food Standards Australian and New Zealand. AUSNUT 2007 (2009) Food Standards Australia and New Zealand. http:// www.foodstandards.gov.au/consumerinformation/ ausnut2007/ (accessed 17 December 2009).

24. Food Standards Agency (2009) Salt reduction targets. http:// www.food.gov.uk/healthiereating/salt/saltreduction (accessed 24 November 2009).

25. Grigis S, Neal B, Prescott J, et al. (2002) A one-quarter reduction in the salt content of bread can be made without detection. Eur J Clin Nutr 57, 616-620.

26. Schofield WN (1985) Predicting basal metabolic rate, new standards and review of previous work. Hum Nutr Clin Nutr 39C, 5-41.

27. Gibson RS (2005) Principles of Nutritional Assessment, 2nd ed. New York: Oxford University Press.

28. Goldberg GR, Black AE, Jebb SA, et al. (1991) Critical evaluation of energy intake data using fundamental principles of energy physiology 1 . Derivaton of cut-off limits to identify under-recording. Eur J Clin Nutr 45, 569-581.

29. Meneton P, Lafay L, Dufour A, et al. (2009) Dietary sources and correlates of sodium and potassium intakes in the French general population. Eur J Clin Nutr 63, 1169-1175.

30. Health Canada (2009) Multi-Stakeholder Working Group on Dietary Sodium Reduction - Summary Report of the Meeting. http://www.hc-sc.gc.ca/fn-an/pubs/nutrition/_ sodium/2009-0513-rapport-report/index-eng.php (accessed 1 December 2009).
31. Institute of Medicine (2009) Strategies to reduce sodium intake. http://www.iom.edu/?ID=59128 (accessed 14 December 2009).

32. New York City Department of Health and Mental Hygiene (2010) Cutting Salt, Improving Health. http://www.nyc. gov/html/doh/html/cardio/cardio-salt-initiative.shtml (accessed 1 February 2010)

33. Webster JL, Dunford EK \& Neal BC (2010) A systematic survey of the sodium contents of processed foods. $A m \mathrm{~J}$ Clin Nutr 91, 413-420.

34. Australian Division of World Action on Salt and Health (AWASH) (2009) AWASH 2008 consumer survey on parents' attitudes to salt and children. http://www.awash.org.au/ documents/Parents_Attitudes_to_Salt_and_Children_Exec_ Summary.pdf (accessed 12 December 2009).

35. Wise PM, Hansen JL, Reed DR, et al. (2007) Twin study of the heritability of recognition thresholds for sour and salty taste. Chem Senses 32, 749-754.

36. Beauchamp GK \& Moran M (1984) Acceptance of sweet and salty tastes in 2-year-old children. Appetite 5, 291-305.

37. Cowart BJ \& Beauchamp GK (1986) The importance of sensory context in young children's acceptance of salty tastes. Child Dev 57, 1034-1039.

38. Sullivan SA \& Birch LL (1990) Pass the sugar, pass, the salt. Experience dictates preference. Dev Psychol 26, 546-551.

39. He FJ \& MacGregor GA (2003) How far should salt intake be reduced? Hypertension 42, 1093-1099.

40. Blais CA, Pangborn RM, Borhani NO, et al. (1986) Effect of dietary sodium restriction on taste responses to sodium chloride: a longitudinal study. Am J Clin Nutr 44, 232-243.

41. Kim GH \& Lee HM (2009) Frequent consumption of certain fast foods may be associated with an enhanced preference for salt taste. J Hum Nutr Diet 22, 475-480. 